\title{
Forme și funcții ale limbajului vag în rezumate ale unor articole publicate în reviste științifice
}

\author{
Gabriela Cusen* \\ Facultatea de Litere, Universitatea Transilvania din Brașov, Bd. Eroilor 29, 500036 Brașov, România
}

\author{
Despre articol \\ Istoric: \\ Primit 5 septembrie 2018 \\ Acceptat 3 octombrie 2018 \\ Publicat 7 mai 2019 \\ Cuvinte-cheie: \\ rezumate ale articolelor din \\ reviste academice \\ limbaj vag \\ componente IMRaD
}

\begin{abstract}
Rezumat
Această lucrare raportează o investigație exploratorie a componentelor (engl. moves) IMRaD ale rezumatelor (Introducere, Metodă, Rezultate și Discuții) care demonstrează gradul de informare în termeni de explicabilitate referențială a textelor academice și utilizarea limbajului vag în rezumate ale articolelor publicate în reviste academice în 2010 și 2011. Domeniile de cercetare asupra cărora se concentrează aceste articole și rezumatele lor sînt: limbă și lingvistică, literatură și studii culturale. Analiza datelor, bazată pe un cadru de analiză existent (Cutting, 2012), a arătat că autorii folosesc limbaj vag-de exemplu, substantive cu sens generic, mecanisme de eschivare (hedging devices), cuantificatori vagi etc.—și că rezumatele constau în principal din componentele introducere și discuții. Rezultatele cercetării asupra redactării rezumatelor articolelor științifice pot fi de folos atît cercetătorilor debutanți care publică astfel de articole, cît și cadrelor didactice universitare care le îndrumă activitatea.
\end{abstract}

\section{Introducere}

În momentul în care cadrele didactice universitare decid să-și publice articolele de cercetare în reviste științifice, trebuie să scrie rezumate ale acestor articole și să respecte instrucțiunile editorilor în acest sens. Această lucrare prezintă un studiu exploratoriu al rezumatelor articolelor publicate într-o revistă academică, „Buletinul Universităţii Transilvania din Brașov” (România), menit să identifice formele și funcțiile limbajului vag folosit de autori și, de asemenea, să se aplece asupra tipului de text reprezentat de rezumatul unui articol științific publicat în reviste academice (RARS) în ceea ce privește componentele IMRaD. Studiul s-a structurat pe baza a două coordonate majore. În primul rînd, s-a impus o trecere în revistă a literaturii de specialitate din două domenii-studiul limbajului vag și descrierea a ceea ce Cutting (2012, p. 283) numește „distribuția componentelor IMRaD (Introducere, Metodă, Rezultate și Discuții” (trad. mea) pe care rezumatele prezente în corpusul analizat în această lucrare pot să le conțină sau nu. Această trecere în revistă se face atît din perspectivă teoretică (vezi, de exemplu, Channell, 1994; Drave, 2001; Cutting, 2007, 2012), cît și în directă legătură cu cercetarea de faţă. În al doilea rînd, perspectiva teoretică menționată a oferit cadrul analitic necesar examinării rezumatelor care constituie materia corpusului cu sursa mai sus precizată.

\section{Limbaj vag (LV): definiţii}

Pornind de la adevărul binecunoscut că ,în orice grup social în care indivizii au interese și cunoștințe comune se folosește nespecificitatea pentru a vorbi despre interesul comun” (p. 193; trad. mea), Channell (1994) afirmă că o expresie sau un cuvînt este vag(ă) dacă:

a) poate fi contrastat $(\breve{a})$ cu un alt cuvînt sau expresie care pare să redea aceeași enunțare;

b) este intenționat vag $(\breve{a})$ și are scopul de a induce în eroare;

c) semnificaţia rezultă din incertitudinea intrinsecă $(1994$, p. 20).

\footnotetext{
*Adresă de corespondență: gabriela.cusen@unitbv.ro.
} 
În acelaşi sens, pentru Cutting (2012, p. 284), limbajul vag este reprezentat de „forme care sînt în mod intenționat neclare, generale și imprecise (...), iar sensul lor este foarte dependent de cunoașterea contextului".

Atunci cînd este vorba despre examinarea mai detaliată a limbajului vag, unii autori, de exemplu Channell (1994, p. 78, 119, 157), au o viziune destul de restrictivă asupra LV și limitează folosirea termenului la „aproximarea cantităților” și la „ referință vagă la categorii”, cum ar fi thingy (în rom. „chestie”) sau whatshisname (în rom. „cum îi zice”). Alți autori, în special Brown \& Levinson (1987, p. 116), adoptă o poziție mult mai puțin restrictivă și includ hedges, cum ar fi I think (în rom. „[eu] cred”) în categoria limbajului vag. Din perspectiva a ceea ce el numește o „abordare mai cuprinzătoare”, Trappes-Lomax (2007, p. 122) consideră că LV este:

(...) orice alegere intenționată a limbajului concepută pentru a reduce gradul de acuratețe, precizie, certitudine sau claritate cu care un referent sau situație (eveniment, stare, proces) este descrisă mai puțin decît ar fi putut fi.

Ceea ce majoritatea definițiilor VL par să aibă în comun este ideea alegerii intenționate a impreciziei de către utilizatorii limbii și abilitatea lor de a se baza mai degrabă pe cunoașterea comună a contextului pentru a-şi transmite gîndurile interlocutorului lor, fie că acesta este cititor sau un ascultător.

\section{Limbajul vag (LV) în scrierea academică: forme și funcții}

Deoarece studiul prezentat aici se concentrează pe examinarea unor rezumate pentru articole științifice publicate în reviste academice (RARS), acest articol se axează doar pe acele forme şi funcții ale LV pe care literatura de specialitate le discută în legătură cu acest tip de text. Astfel, în conformitate cu Cutting (2012, p. 284), cercetătorii din domeniul studiilor LV, care se concentrează pe textul știinţific scris în limba engleză, au fost în principal „preocupați de cuantificatori vagi și hedges; substantivele generale și general extenders au primit o anumită atenție; verbele generale și pronumele nedefinite au primit mai puțină”.

Această secțiune se referă numai la categoriile de cuantificatori vagi, hedges și substantive cu sens generic din perspectiva diferiților specialiști în domeniu, deoarece acestea au fost identificate în rezumatele examinate în cadrul acestui studiu. Aceste categorii și funcțiile asociate lor sînt exemplificate și discutate într-o secțiune ulterioară a acestei lucrări.

În lucrările lui Channell (1994), Kennedy (1987) sau Ruzaitė (2004, 2007), cuantificatorii vagi sînt prezentați ca fiind folosiți în general ca o „problemă de conveniență” atunci cînd autorul consideră că nu este necesară mai multă precizie. Exemple de astfel de limbaj vag ar putea fi: aproximativ 10 subiecți, aproximativ 100 de chestionare, o mulțime de timp, un număr mare de eșantioane. Următoarea categorie, cea reprezentată de hedges, este văzută de Cutting (2012, p. 285) ca un mijloc folosit de autori pentru a-și arăta „angajamentul față de valoarea adevărului enunțării lor”. Pentru hedges, Cutting dă exemple precum „catenativele (verbe care cer complemente non-finite, cum ar fi appear to - „pare să”), operatorii modali (might - „s-ar putea”), adjective (likely - „probabil”) sau adverbe (possibly - „posibil”)” și le urmărește în lucrarea lui Hyland (1996) și în cea a lui Salager-Meyer (1994). În ce privește substantivele generice, în timp ce Halliday \& Hasan (1989) consideră că sînt pseudosubstantive ('dummy' nouns), cum ar fi thing, people and place (în rom., „lucru”, „oameni” și „loc”), Mahlberg (2005) susține că sînt „substantive de înaltă frecvență care își extrag semnificația din funcțiile textuale locale sau din co-text" (trad. mea). Printre exemplele date de Cutting (2012) pentru astfel de substantive generice sînt: feature(s), factor(s), issue(s) (,caracteristică(-ici)”, „factor $(-i)$ ”, ,problemă(-e)”).

O privire asupra literaturii despre LV sugerează că acesta este utilizat în texte academice, cum ar fi rezumatele de jurnal academic analizate aici, atît cu funcții de hedging („eschivare”), cît și cu cele nonhedging („non-eschivare”). Salager-Meyer (1994), Banks (1998), Drave (2001), Trappes-Lomax (2007) și Cutting (2012) identifică și descriu trei funcții de hedging și patru funcții non-hedging ale LV. Cele trei 
funcții de hedging menționate mai sus sînt curtoazia, modestia și prudența și sînt deosebit de relevante pentru categoriile de LV identificate în rezumatele analizate în acest studiu.

Prima funcție de hedging, curtoazia, este adesea calificată drept motiv pentru utilizarea LV. Autorii tind, prin urmare, să folosească LV din „curtoazie”, deoarece uneori afirmațiile lor arată că, în cuvintele lui Trappes-Lomax (2007, p. 131), o fac din „respect pentru cunoștințele prealabile ale publicului” și pare să implice subtextul ,aș putea fi mai explicit, dar s-ar putea să te simţi insultat că detaliez” (trad. mea). Atunci cînd vine vorba de categorii de LV, Banks (1998, p. 17) constată că folosirea unor cuantificatori vagi este o funcție de hedging „practic interpersonală” care arată că scriitorul „se conformează stilului așteptat sau evită comportamentul care îi amenință credibilitatea”.

Cea de-a doua funcție, modestia, poate proveni din preferința autorilor pentru hedging, prin utilizarea limbajului vag, chiar dacă sînt siguri de afirmațiile lor. Acest lucru pare că se datorează faptului că ei consideră necesar să își „,afișeze umilința pentru a minimiza amenințarea credibilității lor” (Cutting, 2012, p. 285). În acest caz, Salager-Meyer (1994, p. 149) constată că, din moment ce „aroganța argumentativă și exuberanța nu sînt bine văzute de comunitatea științifică”, autorul unui text academic folosește LV pentru a spune „nu doresc să mă laud”.

Cea de-a treia funcție, prudența, arată că utilizarea LV este expresia unei ezitări, deoarece autorii sînt îngrijorați într-un fel de eventualele rezultate neconcludente ale studiilor lor. Acesta poate fi cazul în care hedging-ul este „cea mai puternică alegație pe care o poate face cercetătorul prudent” (Salager-Meyer, 1994, p. 151) și astfel utilizarea LV dezvăluie „scepticismul științific și îndoiala”. Potrivit lui Cutting (2012, p. 286), „prudență” înseamnă „nu pot fi mai explicit pentru că nu sînt sigur dacă am dreptate”. Această funcție de hedging este considerată relevantă în cazul RARS examinate aici, deoarece utilizarea limbajului prevenitor poate fi un avantaj pentru autori atunci cînd cercetarea pe care o raportează este incompletă.

Lingviștii a căror contribuție privind funcțiile LV a fost citată mai sus afirmă că autorii de texte academice folosesc LV și pentru motive care nu sînt legate de hedging. Acești teoreticieni examinează patru funcții non-hedging: de conveniențăă, de autoapărare, expresie a poziției de putere și de anticipare. Funcția non-hedging numită conveniență poate fi utilizată de autori probabil pentru că ei consideră că o anume precizie nu poate da o forță substanțială argumentului lor. În acest sens, Ruzaitè (2004, p. 217-239) susține că tipul de LV realizat prin cuantificatori vagi este folosit atunci cînd autorii simt că precizia este „inutilă”, gîndind, probabil, în termenii „aş putea fi mai explicit, dar ar fi irelevant pentru ideea pe care o susțin”. În cazul RARS aceasta poate fi o funcție relevantă, date fiind, de exemplu, constrîngerile impuse de editor în privința numărului de cuvinte pentru rezumate.

Cînd LV este folosit pentru autoapărare, Trappes-Lomax (2007, p. 122-123) arată că autorii „evită precizia pentru a minimiza amenințarea față de propria lor credibilitate”. El afirmă, de asemenea, că utilizatorii LV în contexte academice fac acest lucru deoarece simt nevoia de a nu oferi informații pentru a împiedica contestarea din partea comunității științifice sau pentru a se „proteja împotriva furtului de proprietate intelectuală”. În mod similar, Ruzaitė (2007, p. 231) a investigat folosirea LV de către studenți și profesori și a constatat că au folosit cuantificatori vagi „pentru a-și proteja argumentele împotriva posibilelor critici”. De asemenea, ea explică faptul că, în această situație, utilizatorii LV în scopul autoapărării pot gîndi „nu pot fi mai explicit pentru că nu mai știu”,

Utilizarea LV pentru a exercita putere este o funcție care este exact opusul hedging-ului. Lucrarea lui Fairclough (1989, p. 82-83) este binecunoscută pentru investigarea relației dintre limbă și putere. Unul dintre aspectele relevante pe care le aduce în discuție este faptul că textele exercită o influență asupra cititorului deoarece „impun presupuneri implicite asupra publicului” și, prin urmare, îi încurajează să interpreteze aceste texte pornind de la aceleași ipoteze. Pentru Cutting (2012, p. 286), folosirea LV pentru conturarea unei poziții de putere în textele academice demonstrează dorința scriitorului de a deveni membru al unei comunități științifice și de a le spune cititorilor „puteți vedea că sint un membru al acestei comunități științifice din felul în care utilizez referințe implicite (...)”.

Ultima dintre funcțiile non-hedging este anticiparea. Aceasta pare să se potrivească bine cu ceea ce Cutting (2012, p. 286) numește „caracterul promitent” al RARS în cazul studiului raportat aici. Ea afirmă 
că autorul unui rezumat „preferă să nu vorbească în detaliu despre rezultatele sale deoarece nu dorește să dezvăluie deznodămîntul studiului său; ei doresc să trezească curiozitatea” cititorului care doar răsfoiește un jurnal academic.

Următoarea secțiune a acestei lucrări este o privire asupra literaturii de specialitate care se ocupă cu componentele IMRaD menite să ofere analizei datelor din acest studiu o a doua perspectivă, anume aceea a gradului de informare a rezumatelor articolelor din publicaţii academice.

\section{Componente IMRaD în rezumate de articole publicate în reviste academice}

Mulți dintre autorii care fac cercetare în domeniul redactării rezumatelor textului academic (Halleck \& Connor, 2006; Swales \& Feak, 2009; Cutting, 2012) s-au axat în principal pe rezumatele conferințelor științifice și și-au îndreptat atenția către componentele (moves) cunoscute sub numele de IMRaD, adică Introducerea, Metoda, Rezultatele și componenta de Discuție asupra rezultatelor cercetării. Prima componentă, Introducerea, este, în general, menită să prezinte, în cuvintele lui Cutting (2012, p. 284), „contextul, scopurile [studiului] și apelul la literatura de specialitate" sau, din cauza constrîngerii legate de numărul de cuvinte, plasarea studiului în domeniul științific din care face parte. Componenta Metodă este cea care implică o explicație a modului în care datele pentru studiu au fost atît colectate, cît și analizate. În secțiunea Rezultate din rezumat, autorul prezintă succint concluziile studiului. Componenta finală, Discuția asupra rezultatelor studiului, dă autorului șansa de a interpreta concluziile studiului și, de asemenea, de a discuta „implicațiile și aplicabilitatea” acestuia.

Studiile axate pe rezumate de conferință, cum ar fi cele raportate în lucrările autorilor menționați anterior, au demonstrat că structura IMRaD a acestor texte este luată în considerare de către recenzori și pare să afecteze evaluarea lor înainte de acceptarea prezentărilor la conferințe. De asemenea, se pare că merită menționat faptul că rezultatele acestor studii demonstrează că în analiza rezumatelor de conferință cercetătorii s-au concentrat asupra tuturor componentelor IMRaD care nu au fost neapărat prezente în textele analizate și nu au decis care dintre ele au fost esențiale. De exemplu, Kaplan et al. (1994) au realizat un studiu ale cărui rezultate cantitative au arătat că, deși toate rezumatele din corpusul lor conțin componenta Rezultate, aproape jumătate dintre ele au fost respinse de către recenzori înainte de conferință. Întrun studiu mai recent, Cutting (2012) a constatat că în jumătate din rezumatele lucrărilor de conferință investigate de ea „autorii nu au finalizat analiza și unii nu și-au terminat colectarea datelor, iar rezumatele au constat în principal din Introducere și componenta Metodă”. Celălalt rezultat important al acestor studii arată că toți autorii rezumatelor de conferință folosesc un limbaj vag reprezentat în primul rînd de substantive generice ale căror funcții au fost considerate a fi cele de conveniență sau de anticipare.

Din cîte știu, o investigație similară a RARS este destul de nouă în domeniu. Cu toate acestea, un astfel de studiu ar trebui să conducă la concluzii similare cu cele bazate pe rezumatele de conferință, deoarece ambele tipuri de rezumate se referă la domeniul scrisului academic.

În concluzie, pare să existe un oarecare consens între reprezentanții literaturii de specialitate în legatură cu respectarea componentelor IMRaD în rezumatele lucrărilor academice. În acest sens, rezultatele studiilor privind utilizarea LV în astfel de texte îi conferă doar un rol legat de coeziune și de hedging. Investigarea componentelor IMRaD şi a utilizării LV într-un mic corpus de rezumate de articole academice, bazată pe o adaptare a cadrului analitic oferit de Cutting (2012), este detaliată în secțiunile următoare. Aceasta este precedată de o descriere a corpusului.

\section{Metoda}

Cele două subsecțiuni de mai jos se referă la descrierea și analiza corpusului de date. Exemplele din date sînt discutate pentru a răspunde la cele două întrebări de cercetare de la sub-secțiunea 5.2. Exemplele selectate din corpus sînt în limba engleză pentru că aceasta este limba de redactare a rezumatelor respective și pentru că pe acestea se bazează analiza și mai apoi discutarea rezultatelor studiului. 


\subsection{Datele din acest studiu}

Corpusul de date pentru acest studiu exploratoriu cuprinde 62 de rezumate ale unor articole publicate în 2010-2011 în „Buletinul Universității Transilvania din Brașov”, Seria IV, Nr. 1 (2010) și Nr. 1 și 2 (2011): Filologie și Studii Culturale. Din publicația apărută în 2010, 26 de rezumate sînt din domeniul Limbii și Lingvisticii (L\&L) (avînd între 40 și 255 de cuvinte) și 2 rezumate se concentrează pe Literatură (L) (avînd între 60 şi 109 cuvinte). Nu au existat articole din domeniul Studiilor Culturale (CS) în Buletinul din 2010. Începînd cu anul 2011, frecvența publicării Buletinului a fost de două ori pe an și, astfel, cele două numere din acest an conțin 13 rezumate de articole referitoare la L\&L (avînd între 49 și 130 de cuvinte), 14 rezumate în domeniul L (avînd între 53 și 174 cuvinte) și 7 rezumate în domeniul CS (avînd între 76 și 187 de cuvinte). RARS în sine au fost apoi colectate într-un corpus. Ele sînt anonime în sensul că titlul articolelor, numele autorilor şi afilierea lor academică nu prezintă interes pentru acest studiu. Cu toate acestea, trebuie menționat faptul că, deși toate articolele și rezumatele acestora sînt scrise în limba engleză, deoarece aceasta este limba principală a revistei, autorii sînt vorbitori nativi de limba română.

Pentru a da o indicație a ceea ce solicită consiliul editorial al „Buletinului Universității Transilvania din Braşov" în ceea ce privește redactarea rezumatelor de articole, mai jos este un extras din Instrucțiunile pentru autori menite să ghideze scrierea rezumatelor ${ }^{1}$ :

Rezumatul ar trebui să contureze în mod sintetic toate rezultatele pertinente, într-o formă scurtă, dar inteligibilă. Rezumatul ar trebui să înceapă prin afirmarea clară a scopului lucrării și să se incheie prin formularea celor mai importante concluzii. Vor fi folosite fraze scurte, directe și complete, scrise într-un singur paragraf, fără tab. Rezumatul va fi scris cu Times New Roman 10 pt și va avea 7 ... 10 rînduri.

\subsection{Analiza și discutarea datelor}

Analiza datelor a fost ghidată de următoarele întrebări: 1. Care sînt formele de LV din corpus și care este funcția lor? și 2. Care sînt funcțiile formelor de LV prezente în componentele IMRaD din corpus?

În timp ce prima întrebarea urmărește să îndrepte atenția cercetătorului asupra categoriilor de LV identificate în date, rolul celei de a doua este acela de a ajuta la înțelegerea relației dintre funcțiile formelor de LV și prezența lor în componentele IMRaD ale RARS.

Procesul de analiză a rezumatelor a constat în două etape. În primul rînd, textele au fost marcate manual pentru a identifica categoriile lexicale și gramaticale. În această etapă a analizei a devenit clar că formele de LV utilizate cel mai des în rezumate au fost cuantificatorii vagi, hedges și substantivele generice. În al doilea rînd, componentele IMRaD din rezumate au fost identificate manual, pe baza celor descrise de Cutting (2012) și etichetate după cum urmează: (i) Introducerea: context, obiective și apel la literatura de specialitate $=[$ Intr.]; (ii) Metoda: colectarea și analiza datelor $=[$ Meth.]; (iii) Rezultatele: concluziile $=[$ Res.]; (iv) Discuția: explicații, implicații și aplicații $=[$ Disc. $]$.

Extrasele din rezumate care conţin exemple ale celor trei categorii de LV identificate în date (cuantificatori vagi, hedges și substantive generale), urmate de rezumate complete ale căror structuri IMRaD sînt analizate, sînt citate și discutate mai jos.

(1) Which choice is to be considered adequate is to be discussed on the basis of several theoretical points of view appropriate to the field of translation criticism. (L\&L)

(2) Although at the beginning of the $21^{\text {st }}$ century a part of the population favours a republic, the monarchy is still strong, with the head of state following the motto "All for Norway" (Alt for Norge") (CS)

\footnotetext{
${ }^{1}$ bttp://webbut.unitbv.ro/Bulletin/Series\%20IV/RO/Instructiuni.btml.
} 
(3) To this aim I have chosen an article from a Romanian satirical newspaper, Academia Catavencu, which I found particularly interesting in that it poses a number of problems for the analysis. $(\mathrm{L} \& \mathrm{~L})$

Exemplele (1), (2) și (3) de mai sus provin din două rezumate din domeniul L\&L şi unul din domeniul CS. Cu toate acestea, trebuie menționat faptul că analiza datelor a arătat că în acest corpus au existat foarte puține cazuri de utilizare a unor cuantificatori vagi sau a unor „cuantificatori vagi non-numerici”, cum îi numește Channell (1994, p. 95). Cele trei construcții redate cu Italic în exemplele de mai sus (several, a part of, a number of - „mai multe, o parte din, un număr de”), pot fi de asemenea clasificate în termeni de semnificație conform cadrului lui Channell. Astfel, toate trei ar putea fi considerate „neutre în ceea ce privește cantitatea” (1994, p. 95). Funcția unui astfel de LV a fost considerată a fi cea de conveniență (Cutting, 2012), o funcție non-hedging care arată că autorii pot folosi LV pentru a arăta că o precizie suplimentară nu ar contribui la argumentele lor, sau cea de prudență, care este funcția hedging ce conduce la concluzia că autorii se exprimă cu precauție cu privire la date neconcludente, arătînd în mod sincer scepticism și îndoială față de acestea.

(4) By presenting Arghezi as an exemplary role model, Caraion creates the opportunity to use whatever resemblance might exist between them to transform the justification of Arghezi's actions into an indirect self justification for his own options. (L)

(5) The comparative method is possibly a suitable choice since simultaneous representation is mostly profitable for a balanced attitude to interpreting both the agent and the object, be them the victim and the aggressors or the offenders and the policemen. (L\&L)

În exemplele (4) și (5), hedges (might, un operator modal, și possibly, un adverb modal) sînt folosite pentru a califica angajamentul autorilor față de valoarea adevărată a revendicărilor lor. Funcția acestui tip de LV este cea de modestie, ceea ce înseamnă că autorii preferă să folosească hedging-ul pentru a arăta un fel de smerenie academică și pentru a minimiza amenințarea față de propria lor credibilitate, și cea de prudență, arătînd că autorii sînt 'cercetători scrupuloși' și exprimă onestitate științifică, scepticism și îndoială.

(6) Here, irony is not considered a simple comment or utterance, but also consists of a complex communicative interaction influenced by different factors. (L\&L)

(7) Following Stanley Fish's argument that theory as theory can have no consequences, this article suggests that by focusing on other aspects of theory we can both understand that its death is not a recent episode and that its power may actually reside in its problematic core'. (L)

Exemplele (6) și (7) indică folosirea substantivelor generice, vagi din punct de vedere semantic (different factors și other aspects of theory -în acest caz, grupuri nominale al căror centru este reprezentat de substantive generice) și provin din domeniile L\&L și L. În exemplul (6) (și în cea mai mare parte a corpusului), modificatorul pre-head simplu limitează categoria de semnificație, substantivul rămînînd relativ, vag. Cititorii trebuie să concluzioneze din co-text care sînt acești factori. Aici funcția poate fi cea de conveniență sau de anticipare. Exemplul (7) conține un substantiv generic care are atît un modificator pre-head, cît și un modificator post-head. Acestea din urmă, conform lui Mahlberg (2005), pot fi asimilate partitivelor cu funcție de suport. Foarte important este că autorii tuturor rezumatelor din acest corpus au folosit substantive generice în moduri similare.

(8) [Intro] The paper analyzes the importance of certain stylistic aspects while translating the German tense "episches Präteritum" into Romanian. [Meth] The translation criticism is carried out on Süskind's novel "The Perfume". The paper focuses on the difficulties on rendering the same stylistic values of the epic narration into Romanian. [Results] The difficulties arise, because in German there is only one single tense for narration, the so called epic past tense, while in 
Romanian the translator has three choices-the tenses "perfect compus", "perfect simplu" and "imperfect". [Disc] Which choice is to be considered adequate is to be discussed on the basis of several theoretical points of view appropriate to the field of translation criticism. (L\&L)

(9) [Intro] The present paper intends to apply the fencing game model of irony proposed by Anolli, Infantino and Ciceri (2001). [Meth] The research consists in the comparative approach of some ironical devices from parliamentary debates in Romanian and British politics since 2008 until present. [Intro: aim] The aim of the article is to analyse how irony is accomplished in interaction, namely construction and usage. [Disc] Irony is easily recognisable and it is used as a criticism and as an attack. [Res] Here, irony is not considered a simple comment or utterance, but also consists of a complex communicative interaction influenced by different factors. (L\&L)

(10) [Intro] The fact that literary theory may have exhausted its resources is already common knowledge. Following Stanley Fish's argument that theory as theory might have no consequences, this article suggests that by focusing on other aspects of theory we can both understand that its death is not a recent episode and that its power may actually reside in its problematic core. (L)

Exemplele (8), (9) și (10) de mai sus sînt rezumate ale articolelor care aparţin tuturor celor trei domenii ale jurnalului menționate în introducere. Rezumatele sînt discutate mai jos atît în ceea ce privește utilizarea de către autori a LV, cît și în legătură cu structura IMRaD a acestora. În aceste exemple, abrevierile pentru zonele de cercetare apar între paranteze rotunde: (L\&L), (L) și (CS). Componentele IMRaD identificate în exemple sînt semnalizate între paranteze pătrate.

În primul rînd, modul în care autorii rezumatelor folosesc LV, formele și posibilele sale funcții au fost discutate mai sus. Totuși, în acest punct, este necesară discuția asupra prezenței LV în componentele IMRaD din rezumate. Astfel, cuantificatori vagi, cum ar fi several din exemplul (8), hedges, ca might în exemplul (10), și substantive generice, cum ar fi factors sau aspects cu modificatori pre- și/sau post-head în exemplele (9) și (10), au fost identificate mai ales în componentele Introducere și Discutarea rezultatelor din rezumate împreună cu utilizarea lor ocazională în componenta Metodă. Acest lucru se poate datora faptului că autorii îi lasă pe cititori să se pronunțe asupra semnificației din co-text sau îi invită să găsească răspunsuri în textul integral al articolului.

În al doilea rînd, după cum s-a anticipat, pe baza constatărilor lui Halleck \& Connor (2006) și Cutting (2012), structura IMRaD a RARS nu a avut o repartizare egală a componentelor. O discuție cantitativă poate părea mai puțin relevantă pentru corpusul mic al acestui studiu. Cu toate acestea, faptul că numai două rezumate, ale căror subiecte aparțin domeniului $L \& L$, din cele 62 din corpus conțin toate cele patru componente IMRaD merită luat în considerare. De asemenea, pare interesant (și din nou merită să se țină seama în cercetări similare) că, indiferent de domeniul lor de cercetare, structura a 11 rezumate prezintă doar trei componente (Introducere, Metodă și Discutarea rezultatelor), 25 conţin doar două componente (Introducere și Metodă) și 24 de rezumate constau doar din Introducere (fără indicarea Metodei și Rezultatelor sau Discutarea acestora). Exemplul (8) de mai sus este unul dintre cele două a căror structură conține toate cele patru componente IMRaD pe care se concentrează literatura de specialitate. Exemplele (9) și (10) sînt reprezentative pentru corpus prin faptul că au fie o structură care poate fi confuză pentru cititor, deoarece autorii tind să meargă înainte și înapoi între componente-ca în (9)—, fie rezumatele constau numai din Introducere-ca în (10).

\section{Concluzii: revenire la întrebările de cercetare}

Ca răspuns la întrebările care au condus studiul, pare clar că RARS analizate conțin în principal componentele IMRaD Introducere și Discutarea rezultatelor; componentele Metodă și Rezultate nu sînt frecvente. Formele de LV în aceste componente au fost, în general, substantive generice [de exemplu: activity (-ies), element(s), emphasis, issue(s), perspective(s), problem(s) - „activitate(-ăți), element(-e), accent, problemă(-e), perspectivă(-e)"], ale căror modificatori pre-head (de exemplu: new perspectives, special 
emphasis, optimal strategies, complex activity - „noi perspective, accent special, strategii optime, activitate complexă”) nu aduc mai multă precizie în ce privește semnificația. În plus, pe lîngă funcția de coeziune textuală, substantivele generice au îndeplinit funcțiile hedging de curtoazie și de precauție și funcțiile nonhedging (de conveniență, de anticipare și de autoapărare).

$\mathrm{Cu}$ toate acestea, din moment ce acest studiu are un caracter exploratoriu, concluziile nu sînt deloc generalizabile. Mai mult decît atît, datele analizate în acest studiu au fost extrase din domenii de studiu lingvistice și literare, ceea ce îi poate conferi o valabilitate externă limitată. Într-o notă mai pozitivă, este posibil ca rezultatele unor astfel de cercetări despre redactarea rezumatelor de articole științifice să fie benefice atît pentru autorii novice în scrierea textului academic, cît și pentru specialiștii din mediul academic care le îndrumă activitatea.

Rezultatele acestui studiu exploratoriu pot duce la o activitate mai extinsă în aceeași direcție, iar datele (rezumate) din alte domenii de cercetare (inginerie, medicină, afaceri etc.) ar putea fi colectate într-un corpus mult mai mare, menit să ajute la explorarea modului în care se respectă componentele IMRaD și în ce masură se utilizează LV. Se vor putea astfel examina posibilele diferențe de redactare a rezumatelor între texte care se concentrează asupra studiului limbii, literaturii sau studiilor culturale și alte domenii de cercetare.

\section{Bibliografie}

Banks, D. (1998). Vague 2uantification in the Scientific Journal Article, în „ASp, la Revue du GERAS”, 19-22, p. 17-27, Crossref.

Brown, P. \& Levinson, S. C. (1987). Politeness: Some universals in language usage, Cambridge University Press, Cambridge. Channell, J. (1994). Vague Language, Oxford University Press, Oxford.

Cutting, J. (ed.) (2007). Vague Language Explored, Palgrave Macmillan, New York, Crossref.

Cutting, J. (2012). Vague Language in Conference Abstracts, în „Journal of English for Academic Purposes”, vol. 11, nr. 4, p. 283293, Crossref

Drave, N. (2001). Vaguely Speaking: A corpus Approach to Vague Language in Intercultural Conversations, în Peters, P., Collins, P. \& Cohen, A.S. (eds), New Frontiers of Corpus Research, p. 25-40, Crossref.

Fairclough, N. (1989). Language and Power, Longman, London.

Halleck, G. B. \& Connor, U.M. (2006). Rhetorical Moves in TESOL Conference Proposals, în „Journal of English for Academic Proposals", vol. 5, nr. 1, p. 70-86, Crossref.

Halliday, M. A. K. \& Hasan, R. (1976). Cohesion in English, Longman, London.

Hyland, K. (1996). Talking to the Academy: Forms of Hedging in Science Research Articles, în „Written Communication”, vol. 13, nr. 2, p. 251-281, Crossref.

Kaplan, R. B. et al. (1994). On abstract writing, în „Text”, vol. 14, nr. 3, p. 401-426, Crossref.

Kennedy, G.D. (1987). 2uantification and the Use of English: A Case Study of One Aspect of the Learner's Task, în „Applied Linguistics", vol. 8, nr. 3, p. 264-286, Crossref.

Mahlberg, M. (2005). English General Nouns: A Corpus Theoretical Approach, John Benjamins Publishing Company, Amsterdam, Crossref.

Ruzaitė, J. (2004). Academic Precision Reconsidered: A Corpus-Based Account, în „SKY Journal of Linguistics”, vol. 17, p. 217 247, [online].

Ruzaite, J. (2007). Vague Language in Educational Settings: Quantifiers and Approximators in British and American English, Peter Lang, Frankfurt am Main.

Salager-Meyer, F. (1994). Hedges and Textual Communicative Function in Medical English Written Discourse, în „English for Specific Purposes", vol. 13, nr. 2, p. 149-170, Crossref.

Swales, J. M. \& Feak, C.B. (2009). Abstracts and the Writing of Abstracts, University of Michigan Press, Michigan, Crossref.

Trappes-Lomax, H. (2007). Vague language as a means of self-protective avoidance: Tension management in conference talks, în Cutting, J. (ed.), Vague Language Explored, p. 117-137, Palgrave Macmillan, New York, Crossref. 